\section{Recipe for innovation}

SiR - Your leading article on research foresight (Nature 365, 679-80; 1993) pictures the possible ruin of British research by doltish industrialists, as they try to recover from their past neglect of the opportunities offered them by basic research. There is a lot wrong with UK industry, but useful criticism needs a better understanding of the process of innovation than the one underlying your picture.

Innovation doesn't happen by industry recognizing independently a bright idea from basic research, backing it with money and bringing it to market. As shown by the examples of electronic devices based on semiconductor research and of pharmaceuticals based on molecular biological research, innovation actually results from a close interaction between basic research and industry. Innovation requires that basic researchers learn something about development, production, marketing and finance, without weakening their curiosity-driven research skills - hard work, but rewarding, intellectually and sometimes financially.

The chief purpose of research foresight activity ought to be to promote such contact between researchers and people from industry, aimed both at identifying exciting science and the means for its application. If it is to work well, interaction should be between people active at the bench and in the market, more than between senior academic administrators and industrial directors. As you say in your article, it will have to be a democratic process, in which people participate because it helps their work, rather than because it is felt to be politically expedient.

Basic researchers should therefore support the process of research foresight but try to make it a genuine process of interactive learning. If they succeed, so will UK industry, and then the case for better public funding of basic research will become irresistible.

Gerard Fairtlough

5 Belmont Grove,

London SE135DW, UK

\section{Slide viewer}

SIR - In January 1992, the habit of molecular biologists to present gels as sole results of their research led John Maddox to ask: "Is molecular biology yet a science?" Twenty months later, when attending a conference on molecular chaperones, I realized that his call for more quantitative analysis of the living cell (Nature 355, 201; 1992) has passed unheard. Speakers with backgrounds in cell or molecular biology still present incredibly long series of gels, which, apart from being ugly and streaky, can neither prove nor explain anything.

Some self-reflection on the question "why do we scientists present slides?" leads us to a distinction between two main kinds of pictures: those presenting evidence, and those explaining concepts too complicated to be easily grasped from oral presentation. While gels have a strong negative efficiency with respect to the second task - they don't provide explanations but they make more (visual) explanation necessary - they achieve poor ratings in the first one. The presence of a band for compound $\mathrm{X}$ and the absence of $\mathrm{Y}$ in a gel do not prove anything to the disbeliever - for instance, if the ratio of concentrations is one to three, one can easily stain a gel so that the absence of the minor component is suggested. A densitometric profile of the same gel would at least give a quantitative estimate about what is to be understood by 'absent' and 'present' (one could claim, for example, X to be at least in hundredfold excess over $\mathrm{Y})$. And, if this result is to be appreciated by anybody who has not studied $\mathrm{X}$ and $\mathrm{Y}$ for more than 10 years, this picture should be preceded by a didactic cartoon explaining why we do (or do not) expect to find $\mathrm{X}$ present and $\mathrm{Y}$ absent, and what the implications would be, if we found a different result.

In summary, photographs of simple stupid SDS-gels should be banned from conferences and journals. Pictures are a crucial means of communication among Homo sapiens, so we should waste at least as many thoughts on them as on our words. Of course, there are more goals to the "next slide please" than the two discussed, and one of the others is to make people laugh. This, at least, was inadvertently achieved by one of the contributors at the conference mentioned above with a gel: he presented a single lane of a gel with a single black band on it. Economically thinking, he could use this slide in every talk to "prove" anything.

Michael Gross

Oxford Centre for Molecular Sciences,

New Chemistry Laboratory,

Oxford OX13QT, UK

\section{Understanding of science}

SIR - Carmen Pryce is unfair to the journal Public Understanding of Science in her review (Nature 365, 589; 1993). The journal does not claim to be a magazine for the public, but an academic journal in which those undertaking research in issues in public understanding of science can communicate and share their thinking and results. That process is an essential part of scholarship, and the journal should be judged in that light.

Pryce asks if such a journal is necessary. The Committee on the Public Understanding of Science (COPUS), a body seriously concerned with developing and initiating new activities that promote a greater understanding of science and its methods, can assure her that it is. For us it is important that our schemes are solidly based on an understanding of how the 'public' receives and interprets its information. Educational research has shown the inadequacy of a simple teacher-pupil model. We are also required to evaluate the way in which our activities achieve their ends, an aspect where similarly little research has been done.

Interpreting research findings in public understanding of science is not always easy for those outside the academic discipline, but public understanding is hardly alone in that. Nor does it detract from the importance of the research or the need for a journal in which such results can be communicated.

\section{P. R. Cooper}

\section{Committee on the Public}

Understanding of Science,

c\% Royal Society.

6 Carlton House Terrace,

London SW1Y 5AG, UK

\section{Compulsory read?}

SIR - Nature is tempted to involve "all of Darwin" to defend evolution from California creationists (Nature 364, 746; 1993). To begin with, I suggest that Darwin's The Origin of Species and Journal of Researches be made compulsory reading for the students of California. The risk, of course, is that the former may put many students to sleep while the latter, which was Darwin's favourite, is much more lively and better written. Moreoever, it contains inspirational passages about Christian principles and an essay about the hollow conical pitfalls of the lion-ants of England and Australia, which reads, in part:

There can be no doubt that this predacious larva belongs to the same genus with the European kind, though to a different species. Now what would the sceptic say to this? Would any two workmen ever have hit upon so beautiful, so simple, and yet so artificial a contrivance? It cannot be thought so: one Hand has surely worked throughout the universe. (Voyage of the Beagle, 325; Penguin 1989).

Yes, let "all of Darwin" be used to defend evolution from California creationists.

Forrest M. Mims III

433 Twin Oak Road,

Seguin, Texas 78155, USA 